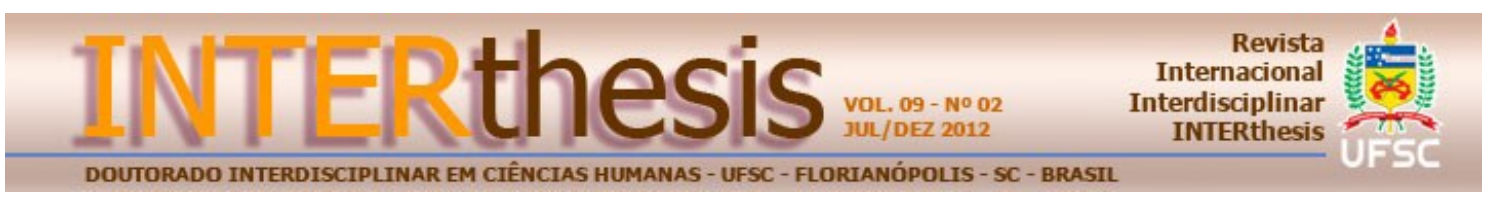

\title{
BIOPODER E RACISMO POLÍTICO: UMA ANÁLISE A PARTIR DE MICHEL FOUCAULT
}

\section{BIOPOWER AND POLITICAL RACISM: AN ANALYSIS FROM MICHEL FOUCAULT}

\section{BIOPODER Y RACISMO POLIITICO: UN ANÁLISIS DESDE MICHEL FOUCAULT}

\author{
Cesar Candiotto ${ }^{1}$ \\ Thereza Salomé D'Espíndula²
}

\section{Resumo:}

A experimentação de novos tratamentos e medicamentos valeu-se dos humanos como cobaias desde que estes se deram conta de que isso poderia colaborar para uma melhoria das condições de vida. Porém, foram produzidas vítimas. Apesar dos grandes benefícios, interesses científicos e individuais podem ser conflituosos gerando complicações, mesmo éticas, como ocorreu no "Caso Tuskegee", um estudo acerca da evolução da sífilis. Após narrar o mesmo, o presente artigo pretende elaborar uma interligação com o biopoder de Foucault. O biopoder inicia-se com o advento do capitalismo e de uma medicina com função de higiene pública, centralização da informação, saneamento e controle de doenças e, imbuída desse papel, passa a exercer um controle do uso dos corpos e da manutenção da saúde da população. Questionando Tuskegee, chega-se a outro ponto ressaltado por Foucault: que para o exercício do poder e da função de morte em um sistema político centrado nele, há que intervir o racismo político. O termo "racismo" empregado por Foucault pode hoje abrigar as diferenças de raça ou cor, de padrões midiaticamente exigidos; ele também pode incluir as situações de exclusão, desigualdades sociais, encarceramento e abandono. Enfim, discute-se a diferença entre relações de poder e processos de dominação no pensamento de Foucault. Para ele, não há relações de poder sem resistências; e onde há dominação, as resistências são inoperantes.

palavras-chave: Foucault. Biopoder. Racismo politico. Vida

\section{Abstract:}

Ever since men realized that experimenting new treatments and drugs on humans could contribute to an improvement of living conditions, human beings have been

\footnotetext{
${ }^{1}$ Doutor em Filosofia pela Pontifícia Universidade Católica de São Paulo, São Paulo, SP, Brasil. Professor do Curso de Filosofia e da Pós-Graduação em Filosofia da Pontifícia Universidade Católica do Paraná, PUCPR, Curitiba, PR, Brasil. Bolsista de Produtividade do CNPQ. Este estudo é apoiado pela Fundação Araucária e pelo CNPQ. E-mail: ccandiotto@gmail.com

2 Mestre em Filosofia pela Pontifícia Universidade Católica do Paraná, PUCPR. Professora da Faculdade Pequeno Príncipe (FPP), Curitiba, PR, Brasil. E-mail: therezapsi@gmail.com
} 
tested as Guinea pigs. Despite all the benefits it might provide to science, many have produced victims. Furthermore, scientific and individual interests might be conflicting, generating ethical complications, such as what happened in the Tuskegee Case, a study on the evolution of syphilis. After narrating this case, the present article intends to establish a connection with Foucault's ideas on Biopower. Biopower has begun with the advent of capitalism and a health and medical system designed to control diseases and information, promote public hygiene and sanitation. Imbued with such role, medicine starts to take control over the population's use of the bodies and the health care maintenance. Other ideas discussed here are the motives behind Tuskegee, emphasized by Foucault, as the usage of power and the function of death in a political system that is centered on Biopower. The term racism, used by Foucault, includes difference in races or color, media-imposed beauty and intellectual standards, social and economic differences, exclusion, imprisonment, abandonment. The differences between relations of power and of constraint according to Foucault's view are also discussed. For him, there is no balance of power without resistance. However, wherever there is domination, resistance becomes inoperative.

Keywords: Foucault. Biopower. Political racism. Life

\section{Resumen:}

La experimentación de nuevos tratamientos y medicaciones se vale de los seres humanos como cobayas desde que ellos se dieron cuenta de que eso podría colaborar para un perfeccionamiento de las condiciones de vida. Sin embargo, han sido producidas víctimas. Pese a los grandes beneficios, los intereses científicos o personales se vuelven conflictivos cuando generan complicaciones, hasta mismo de carácter ético. Eso fue lo que pasó en el "Caso Tuskegge", una investigación respecto de la evolución de la sífilis. Luego de la descripción del mismo, este artículo busca hacer una conexión con los trabajos sobre el biopoder, de Michel Foucault. El biopoder comienza con el advenimiento del capitalismo y de una medicina con rasgos de higiene pública, concentración de la información, saneamiento y control de enfermedades. Encargada de ese rol, la medicina ejerce un control del uso del cuerpo y el mantenimiento de la salud de la población. Cuestionando Tuskegee, se llega a otro punto subrayado por Foucault: en razón del ejercicio del poder y de la función de muerte en un sistema político centrado en él, es imprescindible la intervención del racismo político. El vocablo "racismo" utilizado por Foucault puede hoy anidar las distinciones de raza o color, de estándares demandados por los medios de comunicación; también pude incluir situaciones de exclusión, desigualdades sociales, arresto y abandono. En fin, es discutida la distinción entre relaciones de poder y procesos de dominación en el pensamiento de Foucault. Según él, no hay relaciones de poder sin resistencias; y, donde hay dominación, las resistencias son inoperantes.

Palabras clave: Foucault. Biopoder. Racismo político. Vida.

\section{INTRODUÇÃO}

Desde o momento em que a experimentação com seres humanos apresentou-se como um meio de melhoria das condições de vida em geral, passou- 
se a fazer uso dessa possibilidade. Ao longo do século $X X$, o surgimento de novos tratamentos, medicamentos e vacinas tem sido correlato da intensificação de testes em cobaias humanos, algumas vezes com sucesso e, muitas vezes, ocasionando a antecipação da morte.

Muitos experimentos apresentaram resultados positivos. Foram os casos de vacinas, anestesias, tratamentos contra a febre amarela, o escorbuto e a poliomielite. Entretanto, dentre as populações utilizadas nos experimentos, voluntárias ou não, constam uma incidência maior de imigrantes, escravos, crianças, soldados, prisioneiros, marinheiros e, até mesmo, os próprios pesquisadores. Os experimentos incluíam ingestão, inoculação e tantas outras formas de testagem, de acordo com cada pesquisa.

Não só a medicina, como possa parecer a princípio, mas ainda outras áreas profissionais ligadas à saúde conduziram ou se envolveram com este tipo de experimentação. Dentre elas poderíamos citar a psicologia, a pedagogia, a fisioterapia, a fonoaudiologia, a educação física, a nutrição, a farmácia, a enfermagem, a odontologia.

Uma regulamentação inadequada ou inexistente pode ser um caminho para abusos em pesquisas. Vale lembrar, entretanto, que abusos diferem amplamente de riscos, estes últimos classificáveis como viáveis e legítimos. Abusos não devem jamais ser permitidos, ainda que aquilo classificado como abuso difere em função de um local, época ou cultura.

Neste ensaio pretendemos analisar em que sentido experimentações com seres humanos, como foi o Caso Tuskegee, fazem parte da constituição, desde meados do século XVIII, de um poder centrado na regulação da vida. $E$, principalmente, como esta regulação que objetiva aperfeiçoar as condições de vida da espécie se vale do racismo político ao permitir que subpopulações sejam tratadas simplesmente como corpos vivos disponíveis ao modo de um resíduo mudo a ser gerido por cálculos governamentais.

Para a articulação entre o biopoder e o Caso Tuskegee, apoiamo-nos nos estudos de Michel Foucault dedicados ao poder sobre o corpo e sobre a vida, desde Vigiar e punir ao último capítulo de História da sexualidade, l: a vontade de saber, passando pela última aula de $E m$ defesa da sociedade e pelo texto "A política de saúde no século XVIII", contido na coletânea Microfísica do poder. Auxiliados pela R. Inter. Interdisc. INTERthesis, Florianópolis, v.9, n.2, p.20-38, Jul./Dez. 2012 
incursão à economia interna de sua investigação, argumentamos que diante de experimentos como o que será descrito na sequência, estamos muito mais próximos de um estado de dominação do que propriamente de uma relação de poder. $E$, portanto, neste caso, o biopoder não é uma política sobre a vida ou uma política da vida, mas uma gestão que a torna um meio economicamente rentável e utilizável para a perpetuação de um processo de dominação.

\section{O CASO TUSKEGEE}

Em 1932, no Estado do Alabama (EUA), a partir de um estudo de longa duração acerca da evolução da sífilis, seiscentos pacientes negros sifilíticos e, na sua maioria, de baixo poder aquisitivo, participaram de um experimento. Foi-lhes informado que receberiam um tratamento especial gratuito. Entretanto, permaneceram sem acesso ao mesmo. O estudo só foi realmente suspenso em 1972 - quarenta anos depois de seu início, portanto - quando objeto de denúncia por um jornalista. Esse caso passou a ser amplamente conhecido nos meios de pesquisa com seres humanos como "Caso Tuskegee", a respeito do qual faremos uma breve descrição. ${ }^{3}$

O tratamento anterior à penicilina usado para sífilis utilizava basicamente mercúrio e bismuto e, devido a seus efeitos tóxicos, apresentava um índice de cura em torno de somente 30\%, levando muitos de seus pacientes a óbito. Em 1929, o Serviço de Saúde Pública norte-americano buscava recursos para sanar dificuldades econômicas no tratamento da sífilis. Mas a crise econômica fez retroceder a promessa de fundos; e dois médicos já envolvidos nesse programa, os Drs. Taliaferro Clark e Raymond A. Vondelehr, decidiram acompanhar a evolução dos homens que não haviam sido tratados de sífilis, com o objetivo de levantar novos fundos para tratá-los.

A comunidade em questão era o condado de Macon, no Alabama, economicamente pouco desenvolvido devido a razões sanitárias, particularmente à incidência da sífilis, que acometera aproximadamente $35 \%$ da população em idade

${ }^{3}$ Dentre outras obras consultadas, neste item acompanhamos o texto de GOLDIM, JR. O caso Tuskegee: quando a ciência se torna eticamente inadequada. Disponível em: http://www.bioetica.ufrgs.br/tueke2.html.

R. Inter. Interdisc. INTERthesis, Florianópolis, v.9, n.2, p.20-38, Jul./Dez. 2012 
fértil. Como os fundos esperados para o tratamento não puderam afinal ser obtidos, o acompanhamento prosseguiu em forma de pesquisa, porém destituído de projeto prévio: seu início tinha uma finalidade e seu prosseguimento deu-se a partir de outra.

Essa comunidade compunha-se predominantemente de uma população rural negra, de baixa renda e foi assim que, em 1932, 399 homens portadores de sífilis e 201 sem a doença foram organizados para o acompanhamento. Todos eram avaliados em suas condições físicas periodicamente e Ihes era dito que estavam recebendo tratamento. A contrapartida por sua participação no projeto era o acompanhamento médico, uma refeição quente no dia dos exames e o pagamento das despesas com o funeral, compensações essas que evidenciam ainda mais a precariedade de suas condições econômicas. Durante o projeto foram dados, ainda, alguns prêmios em dinheiro pela participação; e, em 1957, foi concedido a cada um dos participantes um diploma do Serviço de Saúde Pública Norte-Americano agradecendo a participação de 25 anos no estudo.

No entanto, os participantes do estudo de Tuskegee não foram informados que eram portadores de sífilis, nem tampouco sobre os efeitos dessa patologia: a todos os participantes era dito que possuíam sangue ruim, uma denominação comumente utilizada entre os eugenistas à época para justificar, inclusive, a esterilização de pessoas portadoras de deficiências.

Um médico e uma enfermeira negros foram incorporados à equipe do projeto para facilitar a interface entre os sujeitos e a comunidade. Isso veio a se confirmar com a boa adesão dos participantes ao projeto, muito em função do contato sistemático e continuado da enfermeira Rivers que buscava os participantes em casa, em um automóvel especialmente alocado para a pesquisa.

Em 1936 foi publicado o primeiro artigo a partir desse estudo: Untreated syphilis in the male Negro. A comparative study of treated and untreated cases (Cf. VONDERLEHR et al., 1936, pp. 260-265). Esta publicação gerou alguma polêmica, porém logo superada. Em 1961, foi divulgado outro levantamento geral do estudo, com os dados referentes aos trinta anos de acompanhamento: The Tuskegee study of untreated syphilis: the 30th year of observation.(ROCKWELL et al., 1961, pp 792798). Ao longo de toda a duração do projeto foram publicados treze artigos que no próprio título expressavam que o não tratamento era o objetivo do mesmo. Salvo na 
publicação de 1936, os resultados parciais do estudo foram aceitos para apresentação em congressos científicos e não mereceram qualquer restrição por parte da comunidade científica.

A partir de 1945, já havia terapêutica estabelecida para o tratamento de sífilis utilizando penicilina. Em 1947, o serviço de saúde pública norte-americano criou "Centros de Tratamento Rápido" para pacientes com sífilis. Mesmo assim, todos os indivíduos incluídos no estudo continuavam sem receber tratamento por decisão formal do grupo de pesquisadores. Todas as instituições de saúde dos EUA receberam uma lista com o nome dos participantes com o objetivo de evitar que qualquer um deles, mesmo em outra localidade, recebesse tratamento. A inadequação do estudo foi seguindo o padrão conhecido como "slippery slope", isto é, uma inadequação leva a outra e o problema vai se agravando de forma crescente. Nesse caso específico, da omissão do diagnóstico, se evoluiu para o não tratamento, e deste para o impedimento de qualquer possibilidade de ajuda aos participantes.

Em 1968, algumas pessoas que tinham conhecimento do estudo, como o Prof. Peter Bauxum, começaram a demonstrar contrariedade com a continuação do mesmo. Em 1969, a imprensa confirmou 28 mortes por sífilis no estudo. Na mesma época, o Centro de Controle de Doenças de Atlanta, instituição responsável pela condução do projeto nas suas últimas etapas, reiterou a necessidade de prosseguir o estudo pela sua importância; e em 1970 a Associação Médica Norte-Americana também se manifestou favorável à sequência da pesquisa.

$\mathrm{O}$ historiador James $\mathrm{H}$. Jones tomou contato, por acaso, com documentos relativos ao experimento também em 1969, mas pensou que o mesmo já havia sido interrompido quando da divulgação das 28 mortes ocorridas. Posteriormente escreveria o livro Bad Blood: the Tuskegee syphilis experiment (cf. JONES, 1993), relatando os detalhes do projeto como um todo.

Mas foi somente quando a repórter Jean Heller, da Associated Press, publicou no New York Times, em 26/7/72, uma matéria denunciando esse projeto, é que houve uma forte repercussão social e política sobre o mesmo. Após 40 anos de acompanhamento dos participantes, ao término do projeto, somente 74 haviam sobrevivido. Mais de 100 participantes morreram de complicações decorrentes da 
doença; 28 morreram diretamente de sífilis e 40 esposas e 19 recém-nascidos se contaminaram.

O impacto dessa denúncia foi muito grande junto à sociedade, porém o estudo somente foi encerrado meses após. Na época, uma comissão de pessoas vinculada à história da medicina e à bioética, liderada pelo Dr. James Jones, exigiu que o governo norte-americano pedisse desculpas públicas e formais aos oito sobreviventes e às famílias dos demais participantes.

O governo norte-americano pagou mais de dez milhões de dólares em indenizações para mais de 6.000 pessoas, mas não se desculpou pelo abuso. Finalmente, em 16 de maio de 1997, o Presidente Bill Clinton pediu desculpas formais para cinco dos oito sobreviventes que compareceram à solenidade na Casa Branca e para todos os que foram enganados durante o experimento de Tuskegee.

O maior problema levantado pela realização do caso Tuskegee, na verdade, foi o de ter sido elaborado e realizado por pesquisadores supostamente preparados, com supervisão e respaldo de organismos governamentais. Mesmo levando-se em conta alguma relevância inicial, esse estudo teve sua maior inadequação quando, após a descoberta de métodos eficazes de tratamento e cura da doença, não houve sequer uma tentativa de agregar esses novos conhecimentos, o que protegeria assim a vida dos seres humanos nele envolvidos.

Dessa forma, o caso Tuskegee se apresentou como um estudo inadequado, não pelo fato de não oferecer tratamento inicialmente, pois o mesmo ainda não havia em 1932, mas pela omissão do diagnóstico e prognóstico da sífilis para seus portadores. Além disso, o estudo Tuskegee, que se propunha a observar a evolução da doença sem tratamento, repetia o já executado em um estudo realizado na Noruega em 1929.

Releve-se, ainda, que a comunidade científica em geral e editores, comissões científicas de seleção de trabalhos para congressos em particular tiveram acesso a esses dados e não fizeram qualquer questionamento. Somente a indignação social, trazida à tona após quarenta anos na divulgação pela imprensa fez dar um basta a toda a experimentação.

Ainda que não pareça ao enfocarmos esse caso, tentativas de regulamentar pesquisa com seres humanos já existiam em 1932, época do começo de Tuskegee; na verdade, desde o começo do século XX, vinham sendo efetuadas. Em 1900, o R. Inter. Interdisc. INTERthesis, Florianópolis, v.9, n.2, p.20-38, Jul./Dez. 2012 
senador Gallinger propôs uma lei ao Senado Americano, na qual pesquisas seriam respaldadas juridicamente se realizadas por profissionais habilitados e sem envolver seres humanos com menos de vinte anos de idade, por considerar essa uma idade com plena capacidade de tomada de decisão. Também seriam excluídos das pesquisas os bebês, adolescentes, gestantes, nutrizes, idosos e portadores de transtornos mentais.

Em sua proposta o senador sugeria também que uma semana antes da execução do experimento, o pesquisador deveria encaminhar a uma Comissão, criada para esse fim, metodologia e objetivos de seu projeto, bem como permissão por escrito dos partícipes. Dessa forma, a Comissão avaliaria os riscos envolvidos para então conceder a licença para a realização do experimento. O pesquisador ficaria incumbido ainda de entregar relatórios a essa mesma Comissão, dando ciência do andamento do experimento, métodos empregados e resultados obtidos, relatando minuciosamente as intercorrências. Infelizmente, a proposta do Senador Gallinger não foi aceita, muito embora este tenha sido o primeiro documento que estabeleceu regras claras para a realização de pesquisas em seres humanos.

Em 1947 foi criado o Código de Nuremberg como uma primeira normatização da ética em pesquisa, estabelecendo as diretrizes éticas internacionais para pesquisa envolvendo seres humanos. Escrito pelos norte-americanos, o Código de Nuremberg foi parte da sentença do Tribunal de Nuremberg II, como reação às atrocidades do nacional socialismo alemão, principalmente no que diz respeito às ações de pesquisas ocorridas na Segunda Guerra Mundial.

Como outro documento acerca das regras para as pesquisas, a Declaração de Helsinki foi uma manifestação da Associação Médica Mundial. Voltada principalmente para a prática clínica, já passou por inúmeras revisões, relacionandose cada uma delas com transgressões que ainda não haviam sido previstas ou detectadas nas edições anteriores.

Há que se levar em conta, porém, que ao analisar ou mesmo pensar retroativamente um projeto de pesquisa, isso merece alguns cuidados especiais. Os parâmetros que permitiram sua existência e que servirão de base para sua avaliação eram os vigentes à época e não os que ora se apresentam. Os critérios de agora deverão sim servir como base para prevenção de situações similares. 


\section{O BIOPODER E O HOMEM-ESPÉCIE}

Pela história sabe-se que os acontecimentos são encadeados, numa sucessão de reconfigurações. Assim, uma nova forma de governo, por exemplo, não surge do nada; uma nova ferramenta se desenvolve a partir de sucessivos deslocamentos de uma ferramenta já existente; relações de domínio e de poder são criadas em contraste com outras relações de domínio e de poder que a antecedem.

As relações de poder estudadas por Foucault e expostas em suas investigações se constituíram em um estudo de extremo interesse. Destaca-se aqui a emergência do biopoder, o qual, no seu entender, difere do poder predominante na Idade Média, quando o soberano praticamente detinha o direito de vida e de morte de seus súditos.

O novo poder que irrompe em meados do século XVIII parece ter em vista uma atuação sobre o ser humano como espécie biológica, a fim de ter assegurada a existência e a continuidade da mesma.

Nas novas formas de produção que começam a surgir com o advento da Revolução Industrial, esse poder tem um papel crucial para os ajustes da produção. Com a industrialização, as populações rurais migram em grande número para as cidades e passa a ser de suma importância o controle de processos econômicos e dados estatísticos que monitorem a vida. Os processos econômicos atuam na regulação de taxas; o comportamento e os gestos o mais adestrados possíveis evitam desperdícios no tempo e na produção; as ações sobre o corpo e a normalização do prazer contribuem para uma sociedade mais normalizada. $O$ aumento da população urbana aponta para a necessidade de "constituir a cidade como uma unidade, de organizar o corpo urbano de modo coerente, homogêneo, dependendo de um poder único e bem regulamentado" (FOUCAULT, 2000b, p. 86).

Na medida em que a cidade se torna um importante lugar de mercado que unifica as relações comerciais, não simplesmente a nível de uma região, mas a nível da nação e mesmo internacional, a multiplicidade de jurisdição e de poder torna-se intolerável. A indústria nascente, o fato de que a cidade não é somente um lugar de mercado, mas um lugar de produção, faz com que se recorra a mecanismos de regulação homogêneos e coerentes (2000b, p.86). 
O poder sobre a vida se desenvolve principalmente em torno de dois polos: as disciplinas do corpo e as regulações da população.

Em 1975, em Vigiar e punir, Foucault problematizou o corpo como o alvo privilegiado da técnica de poder disciplinar:

o corpo também está diretamente mergulhado num campo político, as relações de poder têm alcance imediato sobre ele; elas o investem, o marcam, o dirigem, o supliciam, sujeitam-no a trabalhos, obrigam-no a cerimônias, exigem-lhe sinais. Este investimento político do corpo está ligado, segundo relações complexas e recíprocas, à sua utilização econômica: é numa boa proporção como força de produção, que o corpo é investido por relações de poder e de dominação (2000a, p. 25).

Os corpos, ao mesmo tempo objetos e alvos do poder, são então submetidos, utilizados, transformados e aperfeiçoados. Desse modo, surge uma forma de adestramento dos corpos. Em vista disso há um trabalho detalhado, uma coerção sem folga, um objeto de controle tal qual uma máquina, investindo-se na eficácia de movimentos, na economia de gestos permitindo "um controle minucioso das operações do corpo" (FOUCAULT, 2000a, p.118). É justamente a técnica de poder disciplinar que atua mais diretamente sobre os corpos. Ela:

Aumenta as forças do corpo (em termos econômicos e de utilidade) e diminui essas mesmas forças (em termos políticos de obediência). Em uma palavra, ela dissocia o poder do corpo; faz dele por um lado uma 'aptidão' para uma 'capacidade' que ela procura aumentar; e inverte por outro lado a energia, a potência que poderia resultar disso e faz dela uma relação de sujeição estrita (2000a, p. 119).

O corpo vigiado da disciplina se presta à contenção de suas vontades, sob o olhar do outro, capaz de puni-lo a qualquer momento em que fuja às regras. Estes processos disciplinares são respostas à grande explosão demográfica e ao crescimento do sistema e da escala de produção. Há, por conseguinte, uma substituição gradativa do poder centrado naqueles que o exercem, como era o caso do poder soberano, por outra modalidade disciplinar centrada na pluralidade de corpos de uma coletividade específica.

Em 1976, em História da sexualidade, l: a vontade de saber (1988), Foucault sublinha que a técnica do poder sobre a vida que emerge em meados do século XVIII incorpora e reconfigura as disciplinas. Porém, a disciplina do corpo é agora acompanhada também da regulação da vida. $O$ biopoder destina-se à preservação R. Inter. Interdisc. INTERthesis, Florianópolis, v.9, n.2, p.20-38, Jul./Dez. 2012 
do homem-espécie, da vida coletiva, do corpo social, dirigindo-se aos acontecimentos aleatórios que ocorrem numa população considerada em sua duração.

Foucault se refere a essas ações políticas implantadas em razão da vida como objeto de poder - um poder que se preocupa com a vida e que ao mesmo tempo busca normalizá-la - a partir de um novo conceito de população entendido a partir de sua regularidade biológica. Portanto, se a disciplina se ocupava dos corpos individualmente dispostos, o biopoder privilegia o corpo social. É preciso, portanto, proteger o corpo social, a vida da população, para tornar viáveis tanto a produção quanto o consumo. O biopoder se situa e se exerce ao nível da vida, da espécie, da raça e dos fenômenos maciços de população: "um poder que tem a tarefa de se encarregar da vida terá necessidade de mecanismos contínuos, reguladores e corretivos" (FOUCAULT, 1988, p.135).

As disciplinas do corpo e as regulações da população constituem, então, os dois polos em torno dos quais se desenvolveu essa organização do biopoder - a gestão calculista da vida a partir dos custos e benefícios econômicos. Não só corpos devem ser adestrados, mas toda uma população passa a ser regulada pelo acompanhamento de taxas variadas (mortalidade, fecundidade, natalidade, vacinação etc.). Dessa relação de poder, nascem ciências, como a estatística, encarregada de legitimar cientificamente aquela relação.

Assim é que, a partir das primeiras medições demográficas, das primeiras estatísticas que vão viabilizar mais tarde outros esquemas de intervenção ainda mais elaborados, o biopoder é exercido pouco a pouco na sociedade ocidental. A visão simples das epidemias se desdobra em forma, natureza, extensão, duração e intensidade de uma determinada doença e população específica, redundando na contabilização da doença como fenômeno de população, como uma "morte permanente que se introduz sorrateiramente na vida, a corrói perpetuamente, a diminui, a enfraquece" (FOUCAULT, 1999, p. 291).

Foucault ressalta, ainda em História da sexualidade, l: a vontade de saber:

este biopoder foi elemento indispensável ao desenvolvimento do capitalismo, que só pode ser garantido a custa da inserção controlada dos corpos no aparelho de produção e por meio de um ajustamento dos fenômenos de população aos processos econômicos (FOUCAULT, 1988, p.132).

R. Inter. Interdisc. INTERthesis, Florianópolis, v.9, n.2, p.20-38, Jul./Dez. 2012 
Além da estatística, a gestão da vida no corpo social coaduna com uma evolução da medicina, voltada para a prevenção da saúde, para a higienização e para a saúde pública, esta última com ações sobre os indivíduos e o meio ambiente coordenadas pelo olhar estatístico e epidemiológico. Em relação à área da saúde em geral e à medicina em particular, estas se inserem como um saber e um poder que incidem de forma imperiosa sobre o corpo e a população, sobre o organismo e os processos biológicos proporcionando, assim, efeitos disciplinares e reguladores. Consequentemente, os médicos penetram paulatinamente nas mais diversas esferas de poder, ao ampliar seu raio de ação inicialmente terapêutico, agora também para direções administrativas e politicamente privilegiadas, caracterizandose como um importante exercício de poder até a época atual: o poder médico.

Inicia-se uma medicina voltada para a coordenação de tratamentos, centralização da informação, saneamento, controle de doenças etc. Nesse novo papel, ela passa a exercer uma regulação minuciosa do uso dos corpos e da manutenção da saúde da população que, embora aparentemente tenha um caráter de proteção, na realidade não deixa de estar voltada para a maximização da produção.

Pela posição que a própria medicina ocupa na sociedade - a de divulgadora de verdades científicas - muitas vezes coloca-se ela mesma como um objeto de desejo e de consumo. No texto "A política de saúde no século XVIII", que encontramos em Microfísica do poder, Foucault agrega: "O médico se torna o grande conselheiro e o grande perito, se não na arte de governar, pelo menos na de observar, corrigir, melhorar o 'corpo' social e mantê-lo em um permanente estado de saúde" (FOUCAULT, 2000b, p.203).

Nos dias atuais, o biopoder assume uma relevância surpreendente, visto que o capitalismo e a tecnociência - amplamente representados não mais apenas pela medicina, mas também pelas demais profissões da área de saúde - são os protagonistas dessa nova forma de poder. O fazer viver assume proporções jamais imaginadas, graças ao advento de novas técnicas de prolongamento da vida, do uso de fármacos em larga escala, do aumento da longevidade nas populações. Assim, o exercício do biopoder, insiste em manter a vida ou mesmo apenas um corpo vivo. Essa manutenção, além de reforçar o poder dessas áreas do saber, torna a duração 
da vida, muitas vezes por meios extraordinários, uma fonte interminável de rentabilidade econômica e experimentação médica.

Como adverte Caponi:

O corpo deixa de ser alguém para ser transformado em um elemento na mecânica geral dos seres vivos que serve de suporte aos processos biológicos de nascimento, mortalidade, saúde e epidemias. O corpo individual importa só na medida em que ilustra os processos que podem indicar o modo de agir, adoecer e de responder aos estímulos do conjunto da população (CAPONI, 2004 p.449).

Foucault reitera no livro de 1976 que o biopoder

foi elemento indispensável ao desenvolvimento do capitalismo, que só pode ser garantido à custa da inserção controlada dos corpos no aparelho de produção e por meio de um ajustamento dos fenômenos de população aos processos econômicos (FOUCAULT, 1988, p. 132).

Este investimento na vida atualmente é acompanhado de uma retomada das relações de poder sobre o corpo de forma muito mais sutil. O prolongamento da vida é correlato de uma nova normalização do corpo, que há algum tempo é objetivado a partir da medicina estética.

\begin{abstract}
A sociedade contemporânea assiste deslumbrada à passagem dos "corpos perfeitos", que invadem progressivamente todos os espaços da vida moderna. A expectativa de corpo das pessoas em relação a esses padrões de beleza é o que provavelmente interliga uma variedade de fenômenos cada vez mais comuns, como a maior incidência de bulimia e anorexia, as malhações e as cirurgias plásticas estéticas (CAPONI; NETO, 2007, p. 570).
\end{abstract}

Portanto, as novas doenças (bulimia, anorexia) constituem o resíduo de um poder que cultiva a beleza do corpo. Assim como, em outro registro bem diferente, a morte dos sifilíticos era também o resto mudo de um poder que procura prolongar a vida de uma população ao lançar mão do racismo político.

\title{
O BIOPODER E O RACISMO POLÍTICO
}

Assim é que se pode relacionar o biopoder ao que ocorreu em Tuskegee, onde seiscentos americanos negros, pouco instruídos e pobres, foram submetidos a um experimento no qual a sífilis foi deixada sem tratamento, mesmo depois de descoberto um tratamento de eficácia comprovada.

R. Inter. Interdisc. INTERthesis, Florianópolis, v.9, n.2, p.20-38, Jul./Dez. 2012 
Quarenta anos de um experimento que poderia ter tido, pelo menos em seus últimos vinte, uma solução para as dores e os efeitos da doença e que, deliberadamente, não foi utilizada. Outros tantos experimentos como esse, envolvendo populações em situação de vulnerabilidade e sem nenhuma autonomia, tiveram lugar ao longo dos últimos tempos. No entanto, Tuskegee em especial, pela sua peculiaridade de ter sido realizado por pesquisadores preparados e com respaldo governamental, nos leva a questionar se em nome da saúde da espécie humana ou da manutenção do corpo social podemos admitir ou, até mesmo, legitimar o fazer morrer de um grupo racialmente definido.

Nessa linha de pensamento, Foucault ressalta que para o exercício do poder e da função de morte em um sistema político centrado no biopoder, há que intervir o racismo político; que dessa forma e nesse momento ele se insere nos mecanismos de Estado, ao operar pelo corte entre quem que deve viver e quem se deixa ou se faz morrer. O biopoder, neste aspecto, estimula a cesura num domínio biológico, ao permitir fragmentar a espécie em subgrupos.

O racismo político opera, ainda, ao modo de uma relação guerreira pela qual, para que alguém viva, é preciso que outro morra. Mais que guerreira, essa relação se mostra eugenista, na medida em que a morte do outro - da raça inferior, do degenerado, do anormal - tende a deixar a vida mais sadia e mais pura.

Rabinow e Rose pensam de maneira similar quando expõem que os racismos

permitem ao poder subdividir uma população em subespécies, para designá-las em termos de um substrato biológico e para iniciar e sustentar um conjunto de relações dinâmicas nas quais a exclusão, o encarceramento ou a morte daqueles que são inferiores pode ser vista como algo que tornará a vida em geral mais saudável e mais pura (RABINOW; ROSE, 2006, p.34).

Encontramos eco de tais ideias em R. Esposito, quando ele, ao referir-se ao biopoder de Foucault, explica que

Uma vez inscrito nas práticas de biopoder, o racismo exerce uma dupla função: a de produzir uma separação num continuum biológico, entre quem deve permanecer com vida e quem, em contrapartida, deve ser atirado para a morte e, mais essencial, a de fixar uma relação direta entre ambas as condições, no sentido de que a morte desses últimos favorece a sobrevivência dos primeiros ( ESPOSITO, 2006, p.175. Tradução nossa). 
Como ressalta Foucault no curso de 1976 Em defesa da sociedade, se esse mecanismo pode atuar é porque tirar a vida não corresponde mais a obter a vitória diante de um adversário, como na relação guerreira, mas a "eliminação do perigo biológico e ao fortalecimento, diretamente ligado a essa eliminação, da própria espécie ou raça" (FOCAULT, 1999, p. 306). Então, nessa modalidade de exercício do poder, o racismo político é condição vital para poder tirar a vida de alguém, para que se possa exercer o direito de matar.

Não se trata exclusivamente de tirar a vida. Ações como expor à morte, multiplicar para alguns (inferiores, de raça ruim etc.) a possibilidade de morte como o ocorrido em Tuskegee, rejeitar, expulsar, no sentido que a psicologia denomina de "morte social", estão inclusos no fazer morrer próprio do racismo político.

$\mathrm{O}$ racismo irá se desenvolver juntamente com o genocídio colonizador e a partir de temas do evolucionismo. As guerras destruirão a raça adversa e regenerarão a própria raça como uma pluralidade unitária e viva. Portanto, a especificidade do racismo moderno não está ligada a mentalidades ou ideologias, mas a vulnerabilidades, a técnicas e tecnologias de poder; está associada ao funcionamento de um Estado que se obriga a utilizar da subdivisão racial da espécie, da eliminação de algumas delas para purificar a outras e, assim, perpetuar uma dominação específica. Depreende-se que um determinado racismo se torna indispensável para poder subtrair a vida de alguém ou torná-la, simplesmente, corpo vivo relegado ao abandono.

Como ressalta Caponi:

\begin{abstract}
Assim que essas populações situadas às margens da sociedade [...] deixam de ser pensadas como sujeitos de direito para passarem a ser pensadas exclusivamente como corpos vivos [...] como pura corporeidade, eles podem passar a ocupar esse espaço publicamente perigoso e ambíguo de uma vida nua (CAPONI, 2004, p. 453).
\end{abstract}

Por racismo no século XXI podemos entender, então, muito mais que a simples segregação racial ou um olhar de desdém lançado, por exemplo, ao portador de necessidades especiais. O termo "racismo" empregado por Foucault pode hoje, com relativa facilidade, abrigar as diferenças de raça e cor, de padrões midiaticamente exigidos, quer no corpo físico, quer no desempenho intelectual. 
Igualmente podem ser inseridos nesse "racismo" as situações de exclusão, desigualdades sociais, encarceramento e abandono.

\section{CONSIDERAÇÕES}

A partir do que foi discutido em relação ao ocorrido em Tuskegee, poderíamos perguntar como o poder poderia ser pensado ou em qual chave analítica ele se inscreve. A estratégia da formação dos conceitos feita por Foucault é novamente pertinente em relação a isso. E, neste caso, ela consiste na diferença que ele estabelece entre relações de poder e estados de dominação, no início dos anos 1980. Uma relação de poder:

só se exerce pelos sujeitos livres, enquanto livres - entendendo-se por sujeitos individuais ou coletivos que tem diante de si um campo de possibilidades onde diversas condutas, diversas reações e diversos modos de comportamento podem acontecer. Não há relações de poder onde as determinações estão saturadas [...] mas apenas quando ele pode se deslocar e, no limite, escapar (FOUCAULT, 1995, p. 244).

E, ainda, acrescenta que

não há relação de poder sem resistência, sem escapatória ou fuga, sem inversão eventual; toda relação de poder implica, então, pelo menos de modo virtual, uma estratégia de luta, sem que para tanto venham a se sobrepor, a perder sua especificidade e finalmente a se confundir. Elas constituem reciprocamente uma espécie de limite permanente, de ponto de inversão possível (1995, p.248).

Quanto aos estados de dominação, eles designam o que normalmente chamamos de "poder" e são exemplificados por aquelas formas de domesticação e violência, frequentemente observáveis em estruturas estáticas e hierárquicas entre as quais se torna quase impossível opor resistências efetivas. São relações assimétricas de poder, em virtude das quais os submetidos têm uma margem de ação quase inexistente. Os estados de dominação "são caracterizados pelo fato de que a relação estratégica é estabilizada nas instituições e a mobilidade, a reversibilidade e a instabilidade da 'ação sobre outra ação', são limitadas" (LAZZARATO, 2000, p. 54-55). Trata-se dos casos em que a capacidade de resistência advinda daqueles que foram sujeitados à experimentação médica, 
farmacológica, política sem consentimento informado, é mínima ou nula, tornando-os facilmente eliminados sob o pretexto do perigo biológico que representam para 0 fortalecimento de uma dada raça. A partir do privilégio da constituição de estados de dominação tem-se um mundo de seres colocados à margem ou excluídos e que, por essa razão, não estão sujeitos às mesmas regras e aos mesmos objetivos da proteção da vida.

Se pensarmos, uma vez mais, na experiência Tuskegee, a princípio, haveria por parte dos sujeitos a ela submetidos alguma capacidade para escapar, para dizer não e abandonar o tratamento; haveria talvez também a possibilidade de se negarem ao experimento, e de, quem sabe, amotinarem-se. No entanto, quando se trata de sujeitos de experimentação a resistência geralmente é mínima, de modo que facilmente passam ao status de cobaias, subpopulações passíveis de serem matáveis, vidas nuas à disposição do aperfeiçoamento da espécie humana. Estamos diante do resíduo emudecido constitutivo de um poder cujo escopo é fazer viver. Figurações gritantes de um biopoder que pouco tem a ver com uma política sobre a vida, sendo esta antes objetivada a partir da gestão calculada dos custos e benefícios característica de um estado de dominação. 


\section{REFERÊNCIAS}

CAPONI, S. N. C.; NETO, P. A medicalização da beleza. Botucatu, Interface Comunic, Saúde, Educ, v.11, n.23, p.569-84, set/dez 2007.

CAPONI, S. N. C. A biopolítica da população e a experimentação com seres humanos. Rio de janeiro, Ciência e Saúde Coletiva, vol. 09 nº . 22, pp. 445-55, abr/jun 2004.

ESPOSITO, R. Bios: Biopolítica e filosofia. Buenos Aires, Amorrortu, 2006.

FOUCAULT, M. Em defesa da sociedade. São Paulo, Martins Fontes, 1999.

$\overline{\text { Graal, } 1988 .}$

História da sexualidade: a vontade de saber. $9^{\mathrm{a}}$ ed. Rio de Janeiro,

. Vigiar e punir. $22^{\mathrm{a}}$ ed. Petrópolis, Vozes, 2000a.

Microfísica do poder. Rio de Janeiro, Graal, 2000b.

Sujeito e poder in Rabinow, P. \& Dreyfuss, H. Michel Foucault: uma trajetória filosófica. Rio de Janeiro, Forense Universitária, 1995. pp. 231-249.

GOLDIM, JR. O caso Tuskegee: quando a ciência se torna eticamente inadequada. Disponível em: http://www.bioetica.ufrgs.br/tueke2.html. Acesso em: 06/10/2012.

JONES, J. H. Bad blood: the Tuskegee syphilis experiment. New York: Free, 1993.

LAZZARATO, M. Du biopouvoir à la biopolitique. Multitudes, n.1, p. 45-57, 2001.

RABINOW, P. e ROSE, N. O conceito de biopoder hoje. Cidade, Política \&Trabalho: Revista de Ciências Sociais, n. 24, p.27-57, Abril de 2006. 
ROCKWELL, D.T. et alli. The Tuskegee study of untreated syphilis: the 30th year of observation. Archives of Internal Medicine, n. 114, p. 792-798, 1961.

VONDERLEHR, R. A. et alli. Untreated syphilis in the male Negro. A comparative study of treated and untreated cases. Ven Dis Inform, n. 17, p. 260-265, 1936.

Dossiê:

Recebido em: Setembro/2012

Aceito em: Outubro/2012 